\title{
The Impact of the Cooperative Mentorship Model on Faculty Preparedness to Develop Online Courses
}

\author{
Larisa Olesova and Susan Campbell \\ George Mason University
}

\begin{abstract}
The 2017 Survey of Faculty Attitudes on Technology conducted by Insider Higher Ed reported on the low percentage of partnerships between university faculty and instructional designers in online course development. Experts were unsurprised because instructional designers (IDs) are underutilized, and their role in higher education is still not clear (Richardson et al., 2019). This qualitative study examined the faculty members' perceptions $(n=11)$ about their mentorship relationships with IDs when they designed and developed asynchronous online courses together. This study also explored factors that may lead to successful mentorship relationships in which IDs are mentors and faculty members are mentees. The results of this study found that faculty perceived that working cooperatively with IDs was effective because they were able to align resources and instructional strategies with learning outcomes; they used time efficiently; and they were also able to apply acquired skills to the development of online courses. Based on semistructured interviews with the university faculty, this study revealed that motivation, open-mindedness, and working relations were the major factors that affected the cooperative mentorship relationships between faculty and IDs to produce and teach an online course of high quality. These results support findings in previous studies on the effectiveness of collaboration between faculty and IDs in higher education. Moreover, this study found evidence that cooperative mentorship relationships between university faculty and IDs can lead to the development of online courses of high quality. Higher education administration, university faculty, and IDs will benefit from the results of this study.
\end{abstract}

Keywords: mentorship, instructional design, asynchronous online teaching and learning

Olesova, L., \& Campbell, S. (2019). The impact of the cooperative mentorship model on faculty preparedness to develop online courses. Online Learning, 23(4), 192-213.

doi:10.24059/olj.v23i4.2089

\section{The Impact of the Cooperative Mentorship Model on Faculty Preparedness to Develop Online Courses}

University faculty increasingly need new skills and knowledge to design, develop, and implement high-quality online instruction as online programs and courses become more and more popular in higher education (Allen \& Seaman, 2015). Partnerships with instructional designers (IDs) could be one way to help them learn and acquire needed skills and knowledge (Kumar \& Ritzhaupt, 2017; Richardson et al., 2019). However, as Richardson et al. (2019) stated, building successful partnerships is difficult as it demands considerable time, and faculty may experience some anxiety or frustration over time management, even though IDs can guide and help them to 
implement new approaches in their teaching practices. In addition to time management, successful partnerships between university faculty and IDs also require communication skills, as discussed in recent studies (Kumar \& Ritzhaupt, 2017; Richardson et al., 2019). Clear and trustful communication is key to establishing open dialogue between partners, understanding the reasons behind suggestions, and relying on each other's competence to improve teaching practices (Richardson et al., 2019). Even though studies have already found evidence of the importance of communication skills for IDs as part of their professional competency (Campbell, Schwier, \& Kenny, 2007; Pan, Deets, Phillips, \& Cornell, 2003), still little is known about faculty perceptions on how these communication skills impact the development of effective partnerships (Richardson et al., 2019). In this study, we suggest that development of trustful and successful relationships between university faculty and IDs can be achieved when both partners are engaged in social reciprocal interactions through a learning process situated in an authentic problem-solving context, such as the course design and development process (Glazer \& Hannafin, 2006). Further, these reciprocal interactions between faculty and IDs should be situated in the context of a mutual and equal partnership to promote truly collaborative efforts in higher education. One of the ways to create a sustainable and equal partnership environment is to engage both partners in mentoring relations (Barczyk, Buckenmeyer, Feldman, \& Hixon, 2011; Glazer \& Hannafin, 2006). Mentoring in higher education has various purposes, including psychological development and career development, junior faculty mentoring, peer mentoring, and mentoring using technology in teaching. Successful mentorship includes the roles and characteristics of mentor and mentee, the stages of the mentoring relationship, and mentoring activities and structures (Gabriel \& Kaufield, 2008). This study defines mentorship as a relationship between a more skilled or experienced person and a lesser skilled or experienced person that has fostered mutual individual growth and the development of specific competencies. These relationships may be long-term or short-term, structured or unstructured, formal or informal, or planned or spontaneous (Barczyk et al., 2011; Gabriel \& Kaufield, 2008). Both the mentor and mentee engaged with and equally contributed to the mentoring partnership in this study. Each brought their own knowledge and experiences: The mentor brought instructional design and technology skills, while the mentee brought teaching experience and subject content knowledge.

Literature has widely examined mentoring for K-12 teachers as an effective approach to improve teaching. However, mentoring is still a newly developing area in higher education. It can be explained by the fact that university faculty are quite independent, highly educated in their disciplines, and entrepreneurial in their work (Barczyk et al., 2011). Most university faculty are trained in a more traditional approach through the use of lectures, papers, and assignments. They generally lack formal education in instructional design to develop and deliver high-quality instruction, specifically in the online environment (Barczyk et al., 2011).

To fill this gap, this study examined faculty perceptions about factors that can lead to successful mentorship relationships with IDs on the design, development, and implementation of high-quality asynchronous online courses.

\section{The Cooperative Mentorship Model}

This study examined mentorship of university faculty using principles of instructional design and online instructional methods to improve the quality of their online courses. The Cooperative Mentorship Model was developed by IDs at a large public university in the midAtlantic region of the United States. It is based on the principles of mentorship where the ID (the mentor) mentors the university faculty (the mentee) who is new to asynchronous online course 
design, development, and teaching. The concept of mentorship reflects the process where people learn new skills, values, and culture directly from others whom they respect and admire. People usually model the behavior of others, especially if the behavior is rewarded (Bandura, 1986). The concept of mentorship is also based on motivation when people look for relationships to engage in competence-seeking behavior. They need mentor relationships because of their inherent feelings of belongingness (Maslow, 1970). A mentorship is one of the ways to satisfy those needs for connectedness and career achievement. In an industrial society, the employer and employee or workers and managers need to unite and share the same values and beliefs to survive. Both need strong leadership and quality. Organizations view mentorship as a low-cost strategy for their employees to master new knowledge and skills (Murray \& Owen, 1991).

Use of the term cooperative reflects the structured and planned process of dividing the four main phases between mentor and mentee. The four phases include (1) planning, (2) production, (3) implementation, and (4) portfolio assessment. Planning is the phase when the mentor introduces the mentee to the instructional design planning process (i.e., needs analysis and aligning learning outcomes and assessments). Production is the phase when the mentor guides the mentee through the design and development process. In this model, the mentee usually completes the planning and production tasks while the mentor facilitates their completion through coaching, scaffolding, and tutoring. The production phase also includes members of the online course network, such as the multimedia specialist, liaison librarian, distance education librarian, registrar's office, assistive technology initiative office, copyright resources office, media services librarian, and Blackboard administrators. Implementation is the phase when the mentor coaches the mentee through a real teaching process in a semester-long, piloted online course. Portfolio assessment is the final phase when the mentee masters teaching skills after finishing piloting the online course and becomes a mentor himself/herself. By the end of this phase, an assessment specialist usually reviews portfolio materials submitted by the mentee. The portfolio includes a teaching reflection, course materials, and the results of the end-of-semester student evaluations.

\section{Review of Literature}

\section{Instructional Designers in Higher Education}

Studies have examined the role of IDs in higher education (Campbell et al., 2007; Dooley et al., 2007; Kenny, Zhang, Schwier, \& Campbell, 2005; Kumar \& Ritzhaupt, 2017; Pan et al., 2003; Richardson et al., 2019) and concluded that the ID's role varies depending on the type of institution. The major role of IDs in any higher education institution is course development and faculty support through a systematic, research-based approach to applying teaching and learning strategies to any subject (Reiser \& Dempsey, 2011). However, the majority of university faculty still do not know what IDs can do because their roles are misinterpreted, and they are sometimes referred to as the "best kept secret" in higher education (Dimeo, 2017). There are still misconceptions, such as when academic institutions perceive IDs as "tech" people, "techies," or part of the information technology (IT) department (Ritzhaupt \& Kumar, 2015). This lack of understanding may be the result of limited institutional efforts or support to communicate what IDs can do. Moreover, if institutions do not promote innovative teaching, it may also create concerns regarding the roles of IDs and their contributions to the improvement of teaching and learning. On the other hand, when institutions support faculty in their desire to learn new approaches to improve their teaching practices, they are usually open and highly motivated to work 
with IDs. Studies show that different types of grants, course releases, funding, and other types of administrative support promote faculty readiness to learn new instructional strategies and collaborate with IDs. Faculty who work closely with IDs on their course improvements usually spread the word about their value and how they can help solve instructional problems. As Kumar and Ritzhaupt (2017) stated, IDs serve as the bridge between teaching and learning needs and technical implementation of those needs. Therefore, in this study, we define instructional design as a systematic process to enhance learning and apply instructional principles to solve real-world problems (Reiser \& Dempsey, 2011).

\section{Mentoring University Faculty}

Previous studies have extensively examined the effectiveness of mentoring university faculty on online teaching and learning in higher education (Barczyk, Buckenmeyer, \& Feldman, 2010; Dittmar \& McCracken, 2012; Drouin, Stewart, \& Van Gorder, 2015; Gabriel \& Kaufield, 2008; Gunawardena et al., 2004; McNaught, 2003; Vaill \& Testori, 2012). The studies have examined different approaches to help faculty develop, teach and/or redesign online courses, including the Learning Technology Mentor Program (LTM; McNaught, 2003); Final Outcome Centered Around Learner (FOCAL) model (Gunawardena et al., 2004); the Mentoring, Engagement, Technology, and Assessment (META) model (Dittmar \& McCracken, 2012); the Online Student Success Project (Drouin et al., 2015); and the Distance Education Mentoring Program (Barczyk et al., 2010).

The mentorship approaches varied by the type of delivery and the role of mentor and mentee within each program. Some models utilized a one-on-one mentoring approach while others were based on cohort learning. Some models used technology to enhance mentorship relations while others focused on traditional face-to-face interactions. For example, McNaught (2003) reported on launching the LTM where mentors, called experienced learning technology mentors (ELTMs), were selected from trained academic staff ranging from teaching or research positions to academic administrative positions. The ELTMs signed a formal contract in which they described the online courses they would be developing alone and with colleagues. The program reported on the benefits for mentors, including publications, opportunities for presentations, professional growth, professional status, and improved IT skills.

The FOCAL model, within the WisCom design model, was designed to utilize the network capabilities of the Internet to develop online "thought communities." The FOCAL model was created to serve as a guide for IDs to design active learning environments in which learners engage in reflective dialogue and collaborative learning (Gunawardena et al., 2004; Gunawardena et al., 2006). Mentoring aided in supporting new members and recognizing people in the community who served as mentors. Both mentors and mentees indicated positive learning gains and knowledge transformation across the community as well as successful implementation for most of the conditions of learning (Gunawardena et al., 2004).

Gabriel and Kaufield (2008) have implemented a reciprocal model of mentoring where a mentor, experienced with online course delivery and pedagogy, worked with six online instructors. The reciprocal model was designed to build a collaborative learning relationship which would benefit both mentor and mentee. The mentoring was scheduled on a just-in-time basis in response to each online instructor's needs during the research project. Both mentor and mentees moved through the stages of initiating the relationship, planning learning opportunities, further developing the relationship, and finally closing and separating at the end of the research study. In this 
mentoring project, both mentor and mentees benefited. For example, the mentor developed an understanding of the process of the postsecondary course development process, while mentees benefited from consistent communication with their mentor on their online teaching.

The Distance Education Mentoring Program developed by a Purdue University Calumet (PUC) team is a four-stage model for mentoring university faculty in higher education to deliver high-quality online instruction (Barczyk et al., 2010; Barczyk et al., 2011; Hixon, Barczyk, Buckenmeyer, \& Feldman, 2011; Buckenmeyer, Hixon, Barczyk, \& Feldman, 2013). The model consists of the learning stage, the teaching stage, the evaluation stage, and the acknowledgement stage (Barczyk et al., 2011, p. 11). The mentors were chosen from qualified faculty members with successful prior experience developing online courses. They were also required to participate in the Quality Matters (QM) online training program to become certified for peer mentoring and quality online course development (MarylandOnline, 2006). Mentees from university faculty applied for admission to the mentorship program, and then they were assigned to mentors. There were several identified benefits for both mentors and mentees in this program. Mentors benefited from an enhanced sense of self-esteem, fulfillment of their own developmental needs, creativity generated by issues and ideas contributed by someone younger or newer, understanding of instructional design and online course development, updated knowledge of new and emerging technologies, and improved teaching by seeing the variety of applications of online course design (Barczyk et al., 2010). Further, a semester-long faculty-to-faculty peer mentorship project called the Online Student Success Project was launched at the same institution. The project aimed at increasing students' passing rates in online courses. Mentors and mentees determined their own timelines and received a monetary incentive (Drouin et al., 2017). The project was effective, as both mentors and mentees felt the mentees' online courses had improved.

Dittmar and McCracken's (2012) META model (Mentoring, Engagement, Technology, and Assessment) is a department-specific model designed to consistently engage and train a large group of geographically dispersed faculty teaching entirely online. Mentoring is provided to all new instructors, instructors identified as needing assistance refining their teaching practices, and to veteran faculty members upon their request. Mentors are appointed through consultation with the departmental chair on the basis of consistent evidence of exemplary skills and abilities in instructional practices, documented student learning outcomes, and technology use.

Vaill and Testori (2012) described the Excellence in Online Education Initiative, the college's three-tiered approach to online faculty development. This initiative combined orientation, mentoring, and ongoing support offered at other institutions. Faculty worked with IDs during orientation. They were then connected to experienced online instructors through the mentoring stage. Mentors were experienced colleagues who shared their online teaching experience success, methodologies, strategies, and tips. Faculty members were satisfied with the mentoring approach because it assisted with course design and increased their preparedness to teach online (Vaill \& Testori, 2012).

Overall, all reviewed studies found that mentorship provided a positive experience for both mentors and mentees. Both learned new approaches, improved their own practices, and benefited from learning emerging technologies. However, the literature in the field of mentorship in higher education examined mostly faculty-to-faculty mentorship in the development and teaching of online courses; it has not identified any studies or conceptual works on ID-to-university-faculty mentoring relationships. This study is an attempt to fill this gap by providing evidence on the 
effectiveness of instructional designers mentoring faculty members to design, develop, and teach online courses based on the principles of the Cooperative Mentorship Model.

\section{Methods}

\section{Research Design}

A phenomenological approach was used to understand a phenomenon by describing faculty members' perceptions of their experiences working cooperatively with IDs as their mentors in this study. The phenomenological research design explored faculty experiences from their own point of view to determine the differences and similarities between their perceived experiences working with their assigned IDs (Patton, 2002).

The research questions included the following:

1. What were the faculty perceptions about the effectiveness of working cooperatively with IDs?

2. What factors impacted the cooperative mentorships between university faculty and IDs to produce and teach asynchronous online courses of high quality?

To answer the two research questions, this study used an interpretive phenomenological analysis (IPA) to conduct an in-depth exploration of a limited number of cases. In such an analysis, participants should represent a homogeneous group to examine similarities and differences between the cases (Smith, Flowers, \& Larkin, 2009).

\section{Instructional Designers}

We researchers for this study are two IDs who were trained and certified in instructional design and helped university faculty develop an asynchronous online course. One ID received an advanced degree in instructional design from a highly ranked higher education institution in the United States. In addition to training in instructional design, this ID also had teaching experience both in face-to-face and online learning environments for both graduate and undergraduate students. This ID also conducted extensive research on the effectiveness of instructional strategies in asynchronous online courses and had multiple publications in research journals. The second ID had over 30 years of experience working with university faculty providing guidance on designing learning activities and incorporating technology. This took place both in the classroom and online across disciplines for both undergraduate and graduate courses.

\section{Participants and Context}

The study was conducted between the spring semester of 2015 and the spring semester of 2017 at a large public university in the mid-Atlantic region of the United States. This IPA study used purposeful sampling (Patton, 2002) because the research goal aimed at examining particular experiences from particular participants. Eleven faculty members across different disciplines, such as communication $(n=2)$, engineering $(n=1)$, linguistics $(n=1)$, bioinformatics $(n=1)$, conflict analysis and resolution $(n=3)$, religious studies $(n=1)$, public policy $(n=1)$, and education $(n=$ 1), who completed the program through the Cooperative Mentorship Model were selected and interviewed on their perceptions working with IDs as their mentors (Table 1). 
Table 1

Participant Overview

\begin{tabular}{lllll}
\hline Participant & Position & Leadership & $\begin{array}{l}\text { Overall teaching } \\
\text { experience }\end{array}$ & $\begin{array}{l}\text { Previous online course } \\
\text { development and/or } \\
\text { online teaching experience }\end{array}$ \\
\hline 1. Betty & Adjunct faculty & No & Since 2007 & No \\
2. Christine & Associate professor & No & Since 2004 & Yes \\
3. Eric & Adjunct faculty & No & Since 2008 & Yes \\
4. Kyle & Professor & No & Since 2004 & No \\
5. Lance & Associate professor & Yes & Since 1992 & No \\
6. Mary & Adjunct professor & No & Since 2012 & Yes \\
7. Mike & Instructor & Yes & Since 1999 & Yes \\
8. Rob & Professor & Yes & Since 1978 & No \\
9. Susan & Assistant professor & Yes & Since 2007 & No \\
10. Sam & Instructor & Yes & Since 1994 & No \\
11. Will & Associate professor & Yes & Since 1989 & Yes \\
\hline
\end{tabular}

Note. $N=11$

\section{Data Collection}

The qualitative data were collected from semistructured interviews. This study used an IPA, which is applicable for the analysis of relatively small sample sizes (Smith et al., 2009). IPA helped examine the convergence and divergence within the sample in some detail (Smith et al., 2009). A set of 10 questions was developed for semistructured interviews. In addition to being the researchers for this study, we were the IDs who worked with the interviewed faculty. To remain unbiased, we interviewed each other's mentees. Each 60-minute interview was recorded and transcribed verbatim.

The interview protocol (see Appendix A) was created to address the four phases of the model to examine faculty perceptions and the factors that impacted the effectiveness of working cooperatively with IDs as their mentors. The questions asked about faculty expectations before they began to work with their mentors; how designing and developing planning materials impacted their vision of their future online course; how the mentorship helped them decide on the approach to use for the activities and assignments; and how the mentorship impacted their technology skills. Other questions focused on organizational issues, including meeting arrangements, availability of the resources, and the average time they spent on the course design and development. Finally, the questions asked whether they were confident in terms of independently developing another online course.

\section{Data Analysis}

The data analysis was guided by the domains and factors for reciprocal interactions reviewed and identified by Glazer and Hannafin in 2006 (see Appendix B). Glazer and Hannafin's 
(2006) reciprocal interactions are influenced by affect, beliefs, environment, culture, cognition, and personality.

We transcribed and coded 11 interviews to find agreement for the developed content categories based on the domains by Glazer and Hannafin (2006). Out of six domains by Glazer and Hannafin (2006), the following domains received the highest frequency: affect, beliefs, environment, and personality. Then, we analyzed the most frequently coded factors within each domain: (1) affect — caring, patience and sensitivity, respect; (2) beliefs - teaching, learning, instructional design, and self-efficacy; (3) environment - shared time and individual time; (4) personality - motivation and open-mindedness. Finally, each identified factor was aligned with the research questions to develop codes in this study to understand the mentorship relationships phenomenon when IDs mentor university faculty.

We agreed to each transcribe and initially code the interviews. Interrater reliability was established using a consensus approach for coding the interview transcripts. After each researcher completed individual coding, we held extensive discussions to clarify interpretations and come to consensus. After reviewing the codes and looking for common codes or codes that could be collapsed, we generated a list of general categories and used them to recode the interviews. Based on general categories, we organized the codes to support the two research questions. In the end, we re-coded data again based on research questions, and this allowed us to look both within and across interviews. First, based on the codes created, the emerging themes were developed. Second, because the primary interest was in the mentees' perceptions of the effectiveness of working cooperatively with their mentors, the portions of the interviews concerning these issues were isolated. Data files were created for each mentee, and interviews were copied and pasted into relevant cells regarding elements of relevance to the research questions. The themes were continually revised until they captured all portions of the data set. Next, the emerging themes were examined by each of the two mentees and compared to finalize themes. The 11 cases were explored and we found that the faculty members represented a homogeneous group based on the criteria we had identified. The use of two researchers to examine the data, first individually and then collaboratively, helped control for simple error and thereby increased the reliability of the results.

\section{Trustworthiness}

This study implemented strategies to be trustworthy using Lincoln and Guba's (1985) four criteria for qualitative studies (Table 2). 
Table 2

Four Criteria for Trustworthiness

\begin{tabular}{ll}
\hline Criteria & Strategies implemented \\
\hline Credibility & $\begin{array}{l}\text { Prolonged engagement of IDs, who are the } \\
\text { researchers of this study, with interviewed faculty } \\
\text { members during more than one academic year }\end{array}$ \\
& $\begin{array}{l}\text { Persistent observation of a mentorship process by } \\
\text { the IDs, who are the researchers of this study }\end{array}$ \\
& $\begin{array}{l}\text { Peer debriefing to provide an opportunity to clear } \\
\text { the mind of emotions and feelings and make good }\end{array}$ \\
judgments & $\begin{array}{l}\text { Purposive sampling representing faculty who } \\
\text { completed the mentorship phases successfully }\end{array}$ \\
Transferability & Thick description of the phenomenon \\
Interview protocol development based on previous \\
studies on mentorship and collaboration of IDs with \\
university faculty \\
Coding by two researchers to justify the accuracy of \\
code interpretation and meaning \\
Researchers interviewed faculty with whom they did \\
not develop mentorship relations to remove biases \\
Audio recordings of all the interviews were \\
electronically archived and saved
\end{tabular}

\section{Results}

The results indicated that the faculty had positive perceptions about the effectiveness of cooperative mentorship. They said they improved not only their skills to develop online courses but also their teaching strategies. The interviewed faculty also shared that they perceived the IDs as their coaches, similar to what Salinas recommended by saying, "Instructional designers have to understand [that the instructor takes on a lot of risk if a course fails] and ... coach them through the process" (as quoted by Dimeo, 2017). The themes of relevancy, efficiency, and competence emerged to answer the first research question. The themes of motivation, open-mindedness, and working relations emerged to answer the second question. Supporting quotes are included from all participating faculty as applicable.

\section{Relevancy}

We defined relevancy as faculty ability to align resources and instructional strategies with learning outcomes based on the nature of the courses. The majority of the faculty had similar perceptions on how mentorship helped them become more focused and organized with the online course structure. They used the words "clear outcomes," "clearly organized," "clear connection between the outcome and skills," "clearer picture," and "very structured" when they explained the process of aligning course learning outcomes with the course vision. When they explained how 
clarity in their online courses was achieved, they always referred to the structure of their online courses. For example, they perceived that the module-based course structure that an ID recommended was very helpful in matching course learning outcomes with weekly activities. They used the words "layout," "matched structure," "line up," "best format," and "bite-size weekly sections." They perceived resources the IDs recommended, such as the tutorial "How to Write Measurable Objectives" or examples of what other faculty had done, as very helpful to understanding how to match learning outcomes with course activities and assignments. Moreover, faculty also shared their reciprocal interaction experience with their IDs when they discussed future course layout. For example, Kyle said,

I wanted to make this sort of closer to the real experience as possible because many of [my undergraduate students] are going to their work place and start doing something on their own. [My instructional designer] designed this [experience] and I said I can't predict they will learn certain things [but] they will be equipped with skills ... I think eventually I am using it as a template and I can implement this in other courses. I knew how to do it and [my instructional designer] taught me. This was extremely useful.

Almost all the interviewed faculty members shared that they implemented the same course outline in their other courses, both online and face-to-face. In addition, Susan and Sam shared that it is still challenging to "tie" what they are "doing in the class to specific learning outcomes." Will and Lance openly shared that they never used explicitly related learning outcomes, but designing online courses during mentorship made them rethink "what they are doing." Now, they are using learning outcomes in face-to-face classes as well "so students know what to expect."

\section{Efficiency}

We defined efficiency as the best use of time related to the tasks that need to be completed during mentorship. Even though all the faculty members shared different perspectives (e.g., on technology, resources, and collaboration), they all expressed that the time spent during mentorship was valuable because of learning opportunities despite the amount of time and work required to complete the online course. The faculty members shared that IDs were equipped with learning principles, and they knew how learning happens. Three faculty members, Mike, Lance and Eric, shared interesting views on their experiences working with their assigned IDs. They explained that none of them had previously received formal teaching training to understand pedagogy and that they were self-taught, mostly modeling others' teaching styles or previous experience as students. All expressed similar concerns that high school and middle school teachers have to be accredited and know "pedagogical things" but not in higher education. But they appreciated the teaching guidance they received during mentorship, including using Bloom's taxonomy to "differentiate levels of knowing" starting from "the basic and then ... intermediate and higher level." For example, Eric said,

Some of the classrooms I taught were not very good as far as the layout. It was really hard to teach in [them]. And then I went to distance and learned so much ... and so a lot of these things that learning philosophy that I had, I never paid any attention or even thought about before. I can see things I should have done differently.

In addition, Kyle explained that the time spent during mentorship was useful and efficient to find better solutions for the course interactivity. He said, 
Probably [I] can learn through the manual but I know this [is] much more efficient for [a] fact based on my own experience that [my ID] quickly taught me how to use Blackboard and I [concentrated] on the content. It was very efficient. That technical assistance from [the ID] simply saved a lot of time for me.... The process of the course implementation [would have been] much slower.

Similarly, Sam echoed that having an ID who understands the online environment for an academic program was crucial and beneficial. Sam perceived that he learned a lot of new technology during mentorship, including a new platform, webcam, and different types of software. Lance continued that "the intensity of the efforts which took place in the summer" was significant because he could adjust the samples provided by the ID for his class. He also realized that he should have started development sooner, as he did not realize how much time it would take. Mary and Susan shared a similar perception that looking at other courses provided by an ID was helpful and "sped up" learning; it also improved skills, as both wanted to "learn as much as possible."

\section{Competence}

In this study, competence refers to the mentees' ability to apply newly acquired skills to the development of online courses. This was the most frequent code that emerged. All the faculty members shared different types of skills they were able to apply during and after mentorship. Among frequently coded skills were technology skills, which is not surprising, as instructional design is the field where faculty learn how to align technology with learning goals. Some of the faculty members did not have technology skills, while others had some-for example, placing items in Blackboard learning management system or creating videos. But during mentorship they all learned new technology skills, such as using Camtasia, Screencast-O-Matic or Adobe Premiere, to record and edit instructional videos; Blackboard Collaborate to facilitate synchronous sessions; Audacity to record audio feedback; or Respondus Lockdown Browser to proctor exams.

Surprisingly, however, in addition to technology skills, the faculty members also shared that they learned skills like online community building, creating online presence, creating inquirybased learning including application of the Community of Inquiry (CoI) framework, facilitation skills, and creating and implementing online interaction through online discussions and group work activities. The faculty members did not separate course development skills and online course teaching skills, as they envisioned both as mutually interrelated skills.

Some faculty focused more on finding solutions to their challenges, such as designing and properly assessing an interactive and engaging online environment similar to their face-to-face class environment. They all shared that they were not sure how new things (solutions) would work, but all were happy that "everything went well." All the solutions had been discussed through reciprocal interactions where both partners played equal roles. For example, Mike said,

The first thing we did was ... an icebreaker. It might have come from the book, I cannot remember who it was who found several nice icebreaker items. It feels like a long time ago but I still use the same icebreaker that the mentor provided.

Kyle shared similar memories of his work with an ID when both were brainstorming solutions to recreate a student interaction experience similar to a face-to-face environment. Kyle designed the new online course in bioinformatics. Kyle said,

One important thing and I do not remember whether it was [the ID's] idea or it was my idea but we jointly decided that it is important that students not just only attend online 
discussions as part of the syllabus but they were required to ask questions. They should not just simply present and listen but they should actively participate in this [synchronous online discussion session].

Sam designed his first online course and was worried about finding solutions to "challenge students" with real-world situations. Sam designed the course in communication, where he envisioned that students would get leadership experience managing a media business. Sam was happy to find the right solution in collaboration with his ID. They both decided to place students in role-based online discussions where they reflected on weekly prompts as future leaders in the media business. However, designing role-based discussions caused an assessment challenge. Sam said,

[The ID] gave me chances to think about how to challenge the students in this environment ... where I would grade them on different types of posts. ... That was another new challenge that I'd never graded in an online environment like this. I was satisfied with the challenge students had. ... I am very confident that I have this skill. So, I am going to use those same techniques in the near future.

To answer the second research question on the factors impacted by the cooperative mentorship on the faculty member's ability to produce and teach asynchronous online course of high quality, we found the following factors: faculty motivation to participate in mentorship, faculty open-mindness to create an online course of high quality, and faculty building trust through working relationships with an ID.

\section{Motivation}

In this study, motivation refers to the reason for participating in and completing the mentorship (e.g., expectations, funding, departmental goals, and personal interest). To find out the reasons these faculty members continued and completed the mentorship, we asked about their expectations when they were assigned to an ID. Some faculty did not have a clear understanding of the ID role in this process. They were sure their assigned ID would be in charge of technology. Some faculty underestimated the differences between designing a traditional course and an online course. They thought it was going to "be a lot easier than it turned out to be." Some faculty were resistant and skeptical. They did not believe that "getting online could duplicate the in-class experience." However, among other reasons, such as "to increase course enrollment" or "to get out-of-state students to come to the program," the reasons to "learn something new," "sharpen thinking about teaching," "improve teaching skills" or to "get ideas on best practices" had the highest frequency in this study. We believe that when faculty engaged in the design and development process and found the process helpful, they continued with the mentorship. They described their experience as "blood, sweat, and tears to get through," "figure out how hard can this be," or "the creation itself was difficult." Despite all of these challenges, all the faculty had positive responses, such as "really got a lot from it and ... very proud of what we [mentor and mentee] created," "there was a lot of learning," and "we [group of instructors] didn't think we would get much out of this process but we've turned ourselves around on this."

\section{Open-Mindedness}

In this study, open-mindedness refers to the mentees' willingness to consider options outside of their current practice. Even though the faculty members we interviewed for this study wanted to learn how to improve their current teaching practice, we also looked at whether they 
were ready to change their practice and whether they were able to think outside of the box to change their current practice. We found that when faculty were involved in reciprocal interactions with their IDs and they both had equal roles, they were open to new ideas. For example, Kyle explicitly shared his approach to mentorship relations with his ID:

I think it is also important ... to come with [an] open mind, and I am talking about myself because I see potential where you need to adjust yourself. Because in my case I taught this course before. I simply [tried] to mimic or reproduce the same approaches or the same way of how to teach the course in online and this [was] wrong. I think I was very lucky that [the ID] immediately explained you have to think differently. That was very useful for me.

Sam and Mike shared similar perceptions on open-mindness:

I had the note, I had the questions, I was all ready to go ... I was going to be having an open mind on how to develop this course not only to keep the curriculum the same as if it were in a classroom but to make it challenging. (Sam)

I think there [was] some talk among colleagues that [online course development] is a whole different world and the process would be quite different and time consuming. So, it was more of a warning [but] I was open to the process. I think it is really important because if you start resisting you're missing out on opportunities. I would say [faculty] need to be open to change and I guess I'm trying to do that. (Mike)

The results also revealed that even though the faculty were open to new ideas, the design process itself was not clear for them. For example, Susan said,

I really didn't have any idea what [course design] was gonna look like but it turned into a really structured course. Things that I could adapt or modify were really helpful.

Further, the results revealed that open-mindness also helped implement new approaches. For example, when Eric reflected on the changes in his course, he said,

Sometimes I've had to come up with alternative things ... and then an ID found a couple of nice things from Harvard Business School and [suggested implementing] a Skype interview [activity].

Lance echoed Eric's reflection on new approaches in his online course:

I wasn't sure how I was gonna do that [online collaborative activity] and I've never seen it. ... The first time I ever saw it I said wow that's pretty cool. ... I added it to some of the things that I taught. Well everything that I did ... all of those different things I didn't even know ... I had never even accepted online submissions and [online tests].

\section{Working Relations}

Working relations can be described as the building of trust between the mentor and mentee. When we coded working relations items, we also looked at what factors built trust and what ID's skills and competence impacted on building trust in these relationships. As all interviewed faculty successfully completed this mentorship, they all went through the process of building trust with their assigned IDs. As previously stated, faculty members mentioned that they were not clear on what the mentorship process would look like and what they would be able to get out of this process. However, everyone agreed that the outcomes of this mentorship were surprising and rewarding for them. 
In this mentorship model, both IDs used a flexible approach to working with faculty members on the design and development of high-quality online courses. This was one of the most important factors that impacted on building trust in relationships. IDs were available through faceto-face meetings, phone, online conference tools, and email. Some faculty prefered face-to-face meetings for opportunities to work on creative elements for their courses, such as new activities and assignments. For example, Betty designed an online course based on a situated learning approach where students met with people who practitice religions (e.g., monks or Buddhists). Though Betty appreciated online communication with her mentor, she emphasized the importance of face-to-face meetings for their flexibility to create activities. On the contrary, Susan found effectiveness in Skype meetings. Susan said that Skype meetings helped her not to "fall off" and to "stay going." She continued that when "something came up" and she "couldn't be on campus this day," flexibility was "really key in keeping continuity." Sam expressed the importance of flexibility in terms of helping him to finish the course development while teaching five classes. He mentioned that he "was able to work around and coordinate everything."

In addition to flexibility, some faculty emphazed an ID's degree, experience, and competence. For example, Rob said,

I did not know who my ID was going to be but it turned out there couldn't have been a better one than [my ID]. She was right. She is very qualified and got a $\mathrm{PhD}$ in this area and her book came out. I tend to be a little bit bold and brassy and she wouldn't let me get away with anything, which was great. That's what I just needed.

Another factor that built trust between mentor and mentee was help and support. For example, when Lance realized that he had started late to develop the course and did not have enough time to complete the full development before the semester, his ID helped with extra things, such as submitting instructional videos for closed-captioning. Lance appreciated the help:

I would send them over where [videos] would be done and put them in and [the ID] took care of all of that.

Another factor that built trust in mentorship relationships was learning curve. For example, Mary said,

We had a lot of meetings [at the] beginning, and then later on when I became more proficient with Blackboard we had less meetings. We only met when I had some questions and when I really need to discuss the key issues. We had a very good relationship and [the ID] was always responsible [for] assisting me with the issue.

Learning curve or scaffolding during mentorship was very important, as the faculty were able to learn at their own pace and based on their needs. This impacted tremendously on building trust between the mentor and mentee. When the faculty member saw that solutions worked based on their level of proficiency and skills, they became more open to accepting advice from their IDs. For example, Mike and Rob shared that their ID gave them "homework to do," and it helped them progress in the course development. For example, Rob said,

I was able to do the things the way I wish to. I felt completely confident because I had been trained well. I worked pretty hard too because [my ID] gave an assignment every week to do. I think I did it pretty much and we talked and we got mutual respect. I felt very comfortable because of the training. 


\section{Discussion}

Following previous studies (Kumar \& Ritzhaupt, 2017; Richardson et al., 2019; Ritzhaupt \& Martin, 2014), this study found evidence of the importance IDs' soft skills in building trust or gaining "buy-in" (Ritzhaupt \& Kumar, 2015) with university faculty during mentorship relationships. Moreover, when IDs have strong persuasive skills, relationship-building skills, and communication skills (Ritzhaupt \& Kumar, 2015), they can help faculty members become successful in teaching high-quality online courses. When working with university faculty who are new to online course design and development, it is very important that IDs are equipped with strong skills to teach them and are able to explain complex learning design elements (Ritzhaupt \& Kumar, 2015). In addition, the relationships that are built on mutual respect and trust where both mentor and mentee bring something to the table can open the door to faculty creativity, openmindedness, and willingness to learn (Pan et al., 2003; Richardson et al., 2019).

Similar to previous studies (Pan et al., 2003; Richardson et al., 2019; Ritzhaupt \& Kumar, 2015), the faculty in this study also had misconceptions about the role of IDs in this mentorship process. IDs were perceived as technical personnel in charge of technology and placing the course content online. However, during the mentorship, IDs' competence on learning theories and overall knowledge of how people learn promoted a better understanding of what IDs can do and helped faculty understand the benefits working with them to create a new online course. In this study, all the faculty perceived that working with IDs helped them develop competence needed for successful online teaching (Martin, Budhrani, Kumar, \& Ritzhaupt, 2019). In addition to the development of technical skills, faculty perceived that the mentorship helped them become successful facilitators who were able to build collaborative online communities through a variety of group work activities and online discussions.

The study indicated that motivated faculty are more likely to build strong working relations with their IDs - their mentors. Similar to Glazer and Hannafin (2006), this study indicated that factors such as faculty motivation and open-mindedness are strong indicators of successful mentorship relationships. These factors are valuable components showing faculty's ability to develop a high-quality online course. The results of this study also revealed that when IDs provide accommodations for faculty members, this greatly impacts the formation of faculty competence to develop the necessary skills to build an online course. These findings support previous research where mentors provided professional development and psychological support to establish good rapport and trust with their mentees (Barczyk et al., 2011). Similar to the study conducted by Buckenmeyer et al. (2013), this study also revealed the quality factors deemed most important to performance. In this study, the mentees were competent in their abilities to select relevant instructional strategies and tools to teach an online course. Also, the interview data indicate that participation in the mentorship positively impacted the way they designed, developed, and taught their courses (Buckenmeyer et al., 2013). Overall, the mentees reported high satisfaction working cooperatively with their mentors, felt their teaching improved, and were able to apply what they learned during mentoring to their teaching more broadly (Buckenmeyer et al., 2013; Richardson et al., 2019). 


\section{Conclusion}

The scholarly significance of this study is an attempt to fill the gap in the literature by providing evidence on successful mentorship relationships between IDs and faculty members to develop and teach online courses. The results in this study revealed the Cooperative Mentorship Model based on reciprocal interactions can be an effective model where the ID mentors the university faculty member who is new to asynchronous online course design, development, and teaching. The model promotes faculty professional development and encourages IDs to serve as models and coaches of strategies and ideas aimed at improving online instruction.

\section{Future Research}

More research is needed to explore how mentorship relationships can be successfully developed based on different institutional structures and approaches to support IDs in their work with university faculty. Moreover, more examination is needed on the factors that contribute to faculty failure to complete mentorship despite institutional support (a grant, in our case). Finally, more research should be conducted on how mentorship can help experienced online faculty and how the model should be different to support this type of university faculty.

\section{Limitations}

This study has some limitations. The first limitation relates to the generalizability of findings due to the sample being from a single university. Findings from other universities may be different due to the models of how IDs collaborate with university faculty. For example, IDs can consult university faculty using an ad hoc model, where development of long-term relationships is not the major goal. Another limitation of this study is the analysis of a single data set (i.e., semistructured interviews). More data sets, such as reflective journals during mentorship, student evaluations before and after mentorship, and students' interviews, should be included to understand the phenomenon of mentorship where IDs are mentors helping university faculty design, develop, and teach an asynchronous online course. 


\section{References}

Allen, I. E., \& Seaman, J. (2015). Grade level: Tracking online education in the United States. Retrieved from http://www.onlinelearningsurvey.com/reports/gradelevel.pdf

Bandura, A. (1986). Social foundations of thought and action. Englewood Cliffs, NJ: Prentice-Hall.

Barczyk, C., Buckenmeyer, J., \& Feldman, L. (2010). Mentoring professors: A model for developing quality online instructors and courses in higher education. International Journal on ELearning, 9(1), 7-26.

Barczyk, C., Buckenmeyer, J., Feldman, J., \& Hixon, L. (2011). Assessment of a university-based distance education-mentoring program from a quality management perspective. Mentoring \& Tutoring: Partnership in Learning, 19(1), 5-24. doi:10.1080/13611267.2011.543567

Buckenmeyer, J., Hixon, E., Barczyk, C., \& Feldman, L. (2013). Does participation in a faculty distance education mentoring program comprehensively improve teaching methods? International Journal on E-Learning, 12(2), 139-152.

Campbell, K., Schwier, R. A., \& Kenny, R. F. (2007). The critical, relational practice of instructional design in higher education: An emerging model of change agency. Educational Technology Research and Development, 57(5), 645-663.

Dimeo, J. (2017, November 1). Why instructional designers are underutilized. Retrieved from https://www.insidehighered.com/digital-learning/article/2017/11/01/reasons-why-facultymembers-dont-collaborate-instructional\#.WmplM4F5D09.facebook

Dittmar, E., \& McCracken, H. (2012). Promoting continuous quality improvement in online teaching: The META model. Journal of Asynchronous Learning Networks, 16, 163-175. Retrieved from http://files.eric.ed.gov/fulltext/EJ971050.pdf

Dooley, K., Lindner, J., Telg, R., Irani, T., Moore, L., \& Lundy, L. (2007). Roadmap to measuring distance education instructional design competencies. Quarterly Review of Distance Education, 8(2), 151-159.

Drouin, M., Stewart, J., \& Van Gorder, K. (2015). Using methodological triangulation to examine the effectiveness of a mentoring program for online instructors. Distance Education, 36(3), 400418. doi:10.1080/01587919.2015.1081735

Gabriel, M. A., \& Kaufield, K. J. (2008). Reciprocal mentorship: An effective support for online instructors. Mentoring \& Tutoring: Partnership in Learning, 16, 311-327. doi:10.1080/13611260802233480

Glazer, E. M., \& Hannafin, M. J. (2006). The collaborative apprenticeship model: Situated professional development within school settings. Teacher \& Teacher Education: An International Journal of Research and Studies, 22, 179-193.

Gunawardena, C. N., Jennings, B., Ortegano-Layne, L. C., Frechette, C., Carabajal, K., Lindemann, K., \& Mummert, J. (2004). Building an online wisdom community: A transformational design model. Journal of Computing in Higher Education, 15, 40-62. doi:10.1007/BF02940929

Gunawardena, C. N., Ortegano-Layne, L., Carabajal, K., Frechette, C., Lindemann, K., \& Jennings, B. (2006). New model, new strategies: Instructional design for building online wisdom communities. Distance Education, 27, 217-232. doi:10.1080/01587910600789613 
Hixon, E., Barczyk, C., Buckenmeyer, J., \& Feldman, L. (2011). Mentoring university faculty to become high quality online educators: A program evaluation. Online Journal of Distance Learning Administration, 14(4). Retrieved from http://www.westga.edu/ distance/ojdla/

Kenny, R. F., Zhang, Z., Schwier, R. A., \& Campbell, K. (2005). A review of what instructional designers do: Questions answered and questions not asked. Canadian Journal of Learning and Technology, La Revue Canadienne De L'Apprentissage Et De La Technologie, 31(1). Retrieved from http://www.cjlt.ca/index.php/cjlt/article/view/147/140

Kumar, S., \& Ritzhaupt, A. (2017). What do instructional designers in higher education really do? International Journal on E-Learning, 16(4), 371-393

Lincoln, Y. S., \& Guba, E. G. (1985). Naturalistic inquiry. Newbury Park, CA: Sage Publications.

Maslow, A. H. (1970). Motivation and personality (2nd ed.). New York: Harper and Row.

Martin, F., Budhrani, K., Kumar, S., \& Ritzhaupt, A. (2019). Award-winning faculty online teaching practices: Roles and competencies. Online Learning, 23(1), 184-205.

Maryland Online. (2006). Quality Matters: Inter-institutional quality assurance in online learning. Retrieved from http://www.qualitymatters.org

McNaught, C. (2003). The effectiveness of an institution-wide mentoring program for improving online teaching and learning. Journal of Computing in Higher Education, 15, 27-45. doi:10.1007/BF02940851

Murray, M., \& Owen, M. A. (1991). Beyond the myths and magic of mentoring: How to facilitate an effective mentoring program. San Francisco: Jossey-Bass.

Pan, C. C., Deets, J., Phillips, W., \& Cornell, R. (2003). Pulling tigers' teeth without getting bitten: Instructional designers and faculty. Quarterly Review of Distance Education, 4(3), 289-302.

Patton, M. Q. (2002). Qualitative research \& evaluation methods. Thousand Oaks, CA: Sage Publications.

Reiser, R., \& Dempsey, J. (2011). Trends and issues in instructional design and technology (3rd ed.). Boston, MA: Pearson.

Richardson, J., Ashby, I., Alshammari, A., Cheng, Z., Johnson, B., Krausse, T., Lee, D., ... Wang, H. (2019). Faculty and instructional designers on building successful collaborative relationships. Educational Technology Research and Development, 67, 855-880.

Ritzhaupt, A. D., \& Kumar, S. (2015). Knowledge and skills needed by instructional designers in higher education. Performance Improvement Quarterly, 28(3), 51-69. doi:10.1002/piq.21196

Ritzhaupt, A. D., \& Martin, F. (2014). Development and validation of the educational technologist multimedia competencies survey. Educational Technology Research and Development, 62(1), 13-33.

Smith, J., Flowers, P., \& Larkin, M. (2009). Interpretative phenomenological analysis: Theory, method and research. Thousand Oaks, CA: Sage.

Vaill, A. L., \& Testori, P. A. (2012). Orientation, mentoring and ongoing support: A three-tiered approach to online faculty development. Journal of Asynchronous Learning Networks, 16(2), 111-119. 
Appendix A

Interview

Study Protocol

Sessions conducted individually with participants

Introduction
Thank you for coming today to assist us with this research project on mentorship.
This study investigates your experience in the planning, producing, and teaching of an
online course mentored by an instructional designer. Also, you will be questioned
about whether the mentorship prepared you to independently produce another online
course. The study will be examining your perceptions about the effectiveness of
working cooperatively with instructional designers. In addition, this study will be
exploring the factors impacting the design and development of high-quality online
courses. You will be asked several questions about the benefits and challenges you
encountered and why it may have been beneficial to work cooperatively with an
instructional designer. Your answers will be recorded. Please be assured that no one
except for the researchers will have access to these recordings. Also, understand that
this interview is voluntary and there is no penalty for withdrawing at any time. We
appreciate your time and effort in participating in the interview today. We expect the
interview to take one to one-and-a-half hours.

\section{Direction for dialogue}

You are included in this study because you successfully completed the planning, producing, and teaching of an online course mentored by an instructional designer as part of a grant from the Office of Distance Education at Mason. At the beginning of the grant period, you were informed about which milestones would be completed and what would be expected by the end of the grant period. Then, you experienced working cooperatively with your assigned instructional designer to plan, produce, and teach. I will be asking you a set of 10 questions. Please be aware that there is no right or wrong answer. Please feel free to discuss your thoughts and perspectives.

Researcher, please record the Day, Time and ID of the participant before beginning the interview.

1. What were your expectations for the process of planning (an instructional designer introduces you to the instructional design process), producing (you design and develop your course), and teaching an online course before you began to work with your assigned instructional designer?

2. Were the resources available at Mason including GMU Library, Assistive Technology Office, Copyright Office, Multimedia and others helpful? Please explain.

3. How did the flexibility provided by the mentors in terms of meeting times and methods (e.g., virtual, telephone, email) impact on the quality of the course (including planning, producing, teaching, and assessing)? 
4. How did the instructional design resources (e.g., articles, instructions, sample rubrics, sample assignments, guidelines) impact the planning, producing, and teaching of your online course?

5. How did developing the course planning materials (e.g., learning outcomes, table aligning learning outcomes and assessments) impact your vision of your future online course?

6. How did the mentorship process help you decide on the design and development approach to use for the activities and assignments included in your online course? Please explain.

7. How did the mentorship process impact the technology skills you used to develop the course content and the selection of tools for your students to use?

8. How many months/semesters did you spend producing (designing and developing) your online course? What is the average amount of time you spent weekly on the production of this course?

9. Tell me about your experience teaching this online course after designing and developing this course with an instructional designer? What do you think worked in your course? What would you like to improve in your course?

a. Follow-on question: Have you taught this course before face-to-face? If so, how was this experience different from teaching this course online?

10. Overall, now that you have planned, produced, taught, and received your portfolio results, how confident are you in terms of independently developing another online course? What are your future plans in this regard? 


\section{Appendix B}

Data analysis guide based on the domains and factors affecting reciprocity by Glazer and Hannafin (2006, p. 187)

\begin{tabular}{|c|c|c|}
\hline Domain & Factors & Sources \\
\hline \multirow[t]{8}{*}{ Affect } & Caring & $\begin{array}{l}\text { Chene and Sigouin (1997), Silva and } \\
\text { Tom (2001) }\end{array}$ \\
\hline & Anxiety level & Hawkey (1997), Manouchehri (2001) \\
\hline & Patience and sensitivity & Waugh et al. (1994) \\
\hline & Enjoyment & Kohler et al. (1997) \\
\hline & Connection to a group & Grams et al. (1997) \\
\hline & Friendly climate & Chene and Sigouin (1997) \\
\hline & Connection to an individual & $\begin{array}{l}\text { Hall and Davis (1995), Manouchehri } \\
\text { (2001) }\end{array}$ \\
\hline & Respect & $\begin{array}{l}\text { Dillon and Stines (1996), Terehoff } \\
\text { (2002) }\end{array}$ \\
\hline \multirow[t]{5}{*}{ Beliefs } & Teaching & $\begin{array}{l}\text { Arnn and Manigeri (1984), McCotter } \\
\text { (2001) }\end{array}$ \\
\hline & Learning & Manouchehri (2001) \\
\hline & Instructional design & Carr (2002), Rogers (1999) \\
\hline & Social obligation & Silva and Tom (2001) \\
\hline & Self-efficacy & Bandura (1986), Hall and Davis (1995) \\
\hline \multirow[t]{6}{*}{ Environment } & Proximity & $\begin{array}{l}\text { Brown and Duguid (1991), Rossman } \\
\text { (1984) }\end{array}$ \\
\hline & Shared time & $\begin{array}{l}\text { Clement and Vandenberghe (2000), } \\
\text { Zahorik (1987) }\end{array}$ \\
\hline & Individual time & Hunter (2001), Lohman (2000) \\
\hline & Human resources & Sandholtz et al. (1994) \\
\hline & Physical resources & Lohman (2000) \\
\hline & Accessibility & Nisan-Nelson (2001) \\
\hline \multirow[t]{6}{*}{ Culture } & Leadership & $\begin{array}{l}\text { Carr (1997), Keedy (1999), Palmer } \\
\text { (1993) }\end{array}$ \\
\hline & Professionalism & Davies et al. (1999) \\
\hline & Curriculum & Garet et al. (2001) \\
\hline & Mutual responsibility & Showers (1985) \\
\hline & Peer feedback & Kohler et al. (1999) \\
\hline & Shared tasks & Jarveka et al. (1999) \\
\hline \multirow[t]{6}{*}{ Cognition } & Common understanding & Hausman and Goldring (2001) \\
\hline & Priority & Zahorik (1987) \\
\hline & $\begin{array}{l}\text { Awareness of learning } \\
\text { behaviors }\end{array}$ & Arnn and Manigeri (1984) \\
\hline & Lower order thinking & Hertzog (2002), Manouchehri (2001) \\
\hline & Higher order thinking & $\begin{array}{l}\text { Little (1982), Clement and } \\
\text { Vandenberghe (2000) }\end{array}$ \\
\hline & Reflection & McCotter (2001) \\
\hline
\end{tabular}


The Impact of the Cooperative Mentorship Model on Faculty Preparedness to Develop Online Courses

\begin{tabular}{lll}
\hline Personality & Assertiveness & Lohman (2000), Zahorik (1987) \\
Motivation & Franke et al. (2001) \\
Responsibility & Hunter (2001) \\
Autonomy & Grossman et al. (2001) \\
Availability & Sandholtz and Wasserman (2001) \\
Open-mindedness & Chene and Sigouin (1997) \\
Organization & Knapp (1997) \\
\hline
\end{tabular}

